DOI: 10.12731/2227-930X-2021-11-2-81-99

УДК 656.071.314

\title{
ОЦЕНКА ЭФФЕКТИВНОСТИ СИСТЕМЫ МОТИВАЦИИ ПЕРСОНАЛА КАК ФАКТОРА ОБЕСПЕЧЕНИЯ КАЧЕСТВА РАБОТЫ НА ПРИМЕРЕ ПРЕДПРИЯТИЯ ЖЕЛЕЗНОДОРОЖНОГО ТРАНСПОРТА
}

\section{Серикова О.Ю., Мартышев А.В., Якимова Л.Д.}

Мотивированнье на качественную работу сотрудники представляют большую иенность для любой компании. Около ста лет кадровый менеджмент изучает данную проблему. Данная статья посвящена вопросу оценки эффективности системы мотивации персонала железнодорожного локомотивного эксплуатаџионного депо. В ней рассмотрены различные подходы отечественных и зарубежных авторов к понятию «мотивачия персонала». Авторами проведена экономическая и сочиальная оченка действующей системы мотивации персонала локомотивного депо, входящего в состав холдинга «Российские железные дороги». Для оченки эффективности системы мотиваџии персонала выграна методи$к а$, основанная на исследовании степени достижения основных экономических и социальных ичелей организации. По результатам оценки выявлены проблемы в системе мотивации персонала, относящиеся к организационно-трудовым условиям труда: низкий уровень информированности персонала о мотивационных программах, а также отсутствие системы оценки мотивации персонала. Третья проблема, относящиеся к сочиально-психологическим условиям труда, заключалась в низком уровне лояльности персонала и вовлеченности в трудовую и общественную деятельность организации. Предложены корректирующие мероприятия по решению выявленных проблем: использование цифровой платформы «Scored» и внедрение сервиса HR Code, функичионирующего на основе использования технологии искусственного интеллекта. 
Ожидаемыми результатами от внедрения данных мероприятий являются: повышение производительности труда за счет роста интереса у сотрудников к работе; рост трудовой активности персонала; повышение материальной заинтересованности в развитии своих компетенций в трудовой сфере; увеличение уровня мотивации персонала; сохранение численного и качественного состава персонала; повышение эффективности реализации стратегии управления. Опыт проведения оценки системы мотивачии персонала может быть полезен в региональных подразделениях локомотивного хозяйства компании «Российские железные дороги».

Ключевые слова: мотивация персонала; система мотиваџии; потребности персонала; качество работы персонала; эффективность

\section{EVALUATING THE EFFECTIVENESS OF THE PERSONNEL MOTIVATION SYSTEM AS A FACTOR TO ENSURE THE QUALITY OF OPERATIONS ON THE EXAMPLE OF THE RAILWAY TRANSPORT INDUSTRY}

\section{Serikova O.Yu., Martyshev A.V., Yakimova L.D.}

Employees motivated for high-quality work are very valuable for any company. This article is focused on evaluating the effectiveness of personnel motivation in railway locomotive operating depots. It reviews different approaches of Russian and foreign authors to the concept of "personnel motivation". The authors offered economic and social analysis of the current personnel motivation system of the locomotive depot, which is a part of the Russian Railways holding company. In order to evaluate the effectiveness of the personnel motivation system, the authors have chosen the methodology of researching the degree of the organization's main economic and social objectives achievement. As a result, the authors identified problems in the personnel motivation system related to the conditions of labor organization: the low level of staff awareness of motivational programs, as well as 
the lack of a system for evaluating staff motivation. The third problem related to the socio-psychological labor conditions was the low level of staff loyalty and lack of involvement in labor and social activities within the organization. The authors proposed corrective measures to solve the above mentioned problems: using the digital platform "Scored" and HR Code service, which is based on artificial intelligence. The expected results of the implementation of these measures are:

- increased productivity due to higher interest in the work of employees;

- increased labor activity of the staff;

- increased personnel financial interest in the development of their competencies;

- increased staff motivation level;

- maintaining the numeric and qualitative staff structure;

- improving the effectiveness of the management strategy.

The experience of personnel motivation system assessment may be useful in the regional divisions of the locomotive facilities of Russian Railways.

Keywords: personnel motivation; motivation system; personnel needs; personnel work quality; efficiency

\section{Введение}

Мотивация сотрудников играет важную роль в работе организации, потому что правильная политика мотивации сотрудников обеспечивает повышение качества работы сотрудников и непосредственно увеличивает производительность труда. «Мотивирование составляет основу управления человеком» $[1$, с. 43]. Система мотивации как инструмент управления трудом должна побуждать сотрудников к повышению качества обслуживания клиентов, а также заинтересовывать специалистов к развитию и повышению своего профессионализма [13]. Еще в 2004 году Т. Hennig-Thurau выделил «оптимальный уровень мотивации» [14, с. 912] в качестве ключевой характеристики персонала как инструмента реализации клиентоориентированного подхода.

В отчете об исследовании Kelly Services «Мотивация персонала 2019» отмечено следующее: как бы не вещало передовое HR-сооб- 
щество о важности и эффективности работы по мотивации персонала, действительность в российских компаниях на сегодня выглядит не радужно. Количество компаний, которые уделяют внимание мотивации персонала на 2019 год увеличилась только на 5\% (по сравнению с 2018 г.), и достигло 52\%. Также в исследовании приводится, что $48 \%$ компаний не применяют никаких инструментов по мотивации персонала [10].

Согласно источника Gallup отмечено, что команды с высоким уровнем мотивации сотрудников более эффективно взаимодействуют с клиентами, демонстрируют более высокую продуктивность и коэффициент удержания, а их рентабельность оказывается выше на 21\% [13]. В связи с этим необходимо уделить чуткое внимание совершенствованию системы мотивации, так как качество и результаты работ сотрудников будут эффективнее и будут отражаться как в росте производительности, так и в росте экономических показателей.

\section{Материалы и методы}

Изучением различных актуальных аспектов мотивации труда персонала организации, а также вопросами построения эффективной системы мотивации занимались на протяжении десятков лет многие зарубежные и российские ученые, что, в результате, привело к возникновению в настоящее время большого многообразия определений как самого понятия «мотивация», так и связанного с ним определения понятия «система мотивации».

Для построения эффективной системы мотивации, являющейся важнейшей функцией менеджмента, необходимо определиться с содержанием понятия «мотивация». Существует большое количество мотивационных тенденций, из которых и складывается понятие мотивации, и которые в той или иной степени свойственны каждому человеку [12]. К сожалению, четкого и общепризнанного определения понятия мотивации не существует. Разные авторы дают определение мотивации исходя из своей точки зрения. В таблице 1 рассмотрим некоторые из определений данного понятия [5]. 
Таблицุа 1.

Определения понятия «мотивация персонала»

\begin{tabular}{|l|l|}
\hline \multicolumn{1}{|c|}{ Автор } & \multicolumn{1}{|c|}{ Определение понятия «мотивация персонала» } \\
\hline $\begin{array}{l}\text { Зайцева Г.Г. } \\
(2000 \text { г.) }\end{array}$ & $\begin{array}{l}\text { Побуждение к активной деятельности личностей, } \\
\text { коллективов, групп, связанное со стремлением } \\
\text { удовлетворить определенные потребности. }\end{array}$ \\
\hline $\begin{array}{l}\text { Уткина Э.А. } \\
(2003 \text { г.) }\end{array}$ & $\begin{array}{l}\text { Состояние личности, определяющее степень активности и } \\
\text { направленности действий человека в конкретной ситуации. }\end{array}$ \\
\hline $\begin{array}{l}\text { Мескона А. } \\
(2003 \text { г.) }\end{array}$ & $\begin{array}{l}\text { Процесс побуждения себя и других к активной деятельности } \\
\text { для достижения личных целей и целей своего предприятия. }\end{array}$ \\
\hline Кибанов А.Я. & $\begin{array}{l}\text { Мотивация представляет собой внутренний процесс } \\
\text { сознательного выбора человеком определенного типа } \\
\text { поведения. }\end{array}$ \\
\hline $\begin{array}{l}\text { Карташова Л.В. } \\
(2010 \text { г.) }\end{array}$ & $\begin{array}{l}\text { Процесс сопряжения определенных целей предприятия и } \\
\text { сотрудника предприятия для наиболее полного удовлетворения } \\
\text { потребностей обоих, мотивация также представляет собой } \\
\text { систему различных способов воздействия на персонал для } \\
\text { достижения личных целей сотрудника и целей предприятия. }\end{array}$ \\
\hline $\begin{array}{l}\text { Виханский О.С., } \\
\text { Наумов А.И. }\end{array}$ & $\begin{array}{l}\text { Мотивация представляет собой совокупность внутренних } \\
\text { и внешних движущих сил, которые непосредственно } \\
\text { побуждают человека к деятельности, а также задают } \\
\text { границы и формы деятельности и непосредственно } \\
\text { придают этой деятельности направленность, которая } \\
\text { ориентируется на достижение определенных целей } .\end{array}$ \\
\hline Егоршин А.П. & $\begin{array}{l}\text { Процесс побуждения человека к деятельности для } \\
\text { достижения определенных целей. }\end{array}$ \\
\hline
\end{tabular}

Таким образом, можно отметить, что существующие сегодня подходы к определению понятия «мотивация» классифицируются следующим образом: к первой группе относятся одномерные («простые»), а ко второй - многомерные («сложные») определения [2].

«Простые» определения включают:

- понимание мотивации как состояния сознания субъекта, как процесса формирования у него движущей силы для дальнейших действий;

- понимание мотивации как эффекта влияния управления технологическими процессами на личность.

«Сложные» определения включают:

- анализ мотивации с помощью вспомогательного приема при установлении классификации («процесс - структура»); 
- рассмотрение мотивации в следующих аспектах: предметном, атрибутивном и функциональном [8].

Обобщая все вышесказанное, можно отметить, что мотивация представляет собой с одной стороны, процесс побуждения себя и других к достижению личных целей или целей организации, а с другой стороны - процесс сопряжения целей организации и целей работника для наиболее полного удовлетворения потребностей обоих. Это система различных способов воздействия на убеждения персонала для достижения намеченных целей предприятия. «Проблема мотивации труда особенно актуальна для Красноярского края, так как в условиях сурового климата и тяжелого физического труда ... работников необходимо заинтересовывать различными способами» [11, с. 71].

Для оценки эффективности системы мотивации персонала в Локомотивном эксплуатационном депо ОАО «РЖД» была выбрана методика, основанная на исследовании степени достижения основных экономических и социальных целей организации. Продвижение корпоративных ценностей холдинга «from mission to job levels, job competencies, subcompetencies and their indicators» [16, c. 613] peализованы в системе управления персоналом посредством корпоративной модели компетенций. Согласно данной модели, «сотрудник ОАО «РЖД» должен быть ориентирован, прежде всего, на инновативность, клиентоориентированность, ответственность за результат» [7, с. 127]. Соответственно, данные установки должны лежать в основе системы мотивации работников данной организации.

Результаты. Экономическая эффективность HR-проектов обычно представляет интерес для менеджмента компании в сфере целесообразности кадровых изменений. К сожалению, подсчитать экономическую эффективность программ мотивации в чистом виде сложно из-за сложности оценки результата в денежном выражении, что является следствием внедрения той или иной мотивационной программы [12]. В таблице 2 приведен расчет показателей экономической эффективности системы мотивации персонала исследуемого депо. 
Таблицуа 2.

Оценка экономической эффективности системы мотивации персонала депо

\begin{tabular}{|c|c|c|}
\hline Показатель & Формула расчета & Расчет \\
\hline $\begin{array}{l}\text { Производительность } \\
\text { труда (ПТ) }\end{array}$ & $\begin{array}{l}\qquad \Pi \mathrm{Q}=\frac{\mathrm{Q}}{\mathrm{Ч}_{\text {c.сп }}} \\
\text { где Q - объем работы; } \\
\mathrm{Ч}_{\text {с.сп. }}-\text { ср. списоч. числ. персона- } \\
\text { ла }\end{array}$ & $\begin{array}{c}\Pi \mathrm{T}=\frac{24914900}{711}= \\
=35 \text { 042, } 1 \text { ткм.бр./чел. }\end{array}$ \\
\hline $\begin{array}{l}\text { Коэффициент опере- } \\
\text { жения }\left(\mathrm{K}_{\text {оп. }}\right)\end{array}$ & $\begin{array}{l}\mathrm{K}_{\text {оп }}=\frac{\mathrm{T}_{\text {п.т. }}}{\mathrm{T}_{\text {3.п. }}} \\
\text { где } \mathrm{T}_{\text {п.т. }}-\text { темпы роста произво- } \\
\text { дительности труда; } \\
\mathrm{T}_{\text {з.п. }}-\text { темпы роста 3. пл. }\end{array}$ & $\mathrm{K}_{\mathrm{oII}}=\frac{100,2}{86,8}=1,15$ \\
\hline Зарплатоемкость (ЗЕ) & $\begin{array}{l}\qquad 3 \mathrm{E}=\frac{\Phi_{\text {з.п. }}}{\mathrm{B}} \\
\text { где } \Phi_{\text {з.п. }}-\text { фонд з.пл., руб.; } \\
\text { В - выручка от реализации про- } \\
\text { дукции, руб. }\end{array}$ & $3 E=\frac{302962 \text { тыс. руб. }}{621987 \text { тыс. руб. }}=0,49$ \\
\hline
\end{tabular}

По оценке экономической эффективности системы мотивации персонала Локомотивного эксплуатационного депо можно отметить, что все показатели анализа соответствуют нормам для данного предприятия в своей отраслевой специфики функционирования. Далее необходимо оценить и социальную составляющую действующей системы мотивации персонала депо.

Оценка социальной эффективности системы мотивации персонала данной организации проводилась с помощью метода интервьюирования с руководителями подразделений, опросов сотрудников и наблюдения. Результаты оценки приведены в таблице 3 [6].

Таким образом, анализируя таблицу 3 , можно выделить, что в депо сумма баллов по оценке социальной эффективности мотивации персонала составила 78 из 136 (57\%). В связи с этим можно сделать вывод о том, что система мотивации персонала имеет достаточно низкий показатель эффективности в соответствии с отраслевой спецификой функционирования предприятия, что говорит о наличии проблем в действующей системе мотивации работников. 
Таблицуа 3.

\section{Оценка социальной эффективности системы мотивации персонала депо}

\begin{tabular}{|c|c|c|c|c|c|c|}
\hline \multirow[b]{3}{*}{$\begin{array}{l}\text { № } \\
\Pi / \Pi\end{array}$} & \multirow[b]{3}{*}{ Наименование компонентов } & \multicolumn{5}{|c|}{ Уровень состояния компонентов } \\
\hline & & \multicolumn{2}{|c|}{ Слабые стороны } & \multirow[b]{2}{*}{ 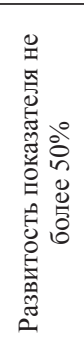 } & \multicolumn{2}{|c|}{$\begin{array}{l}\text { Сильные } \\
\text { стороны }\end{array}$} \\
\hline & & 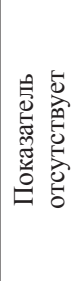 & 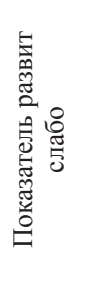 & & 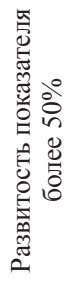 & 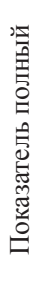 \\
\hline 1 & 2 & 3 & 4 & 5 & 6 & 7 \\
\hline \multicolumn{7}{|c|}{1 блок: «Уровень удовлетворенности персоналом разными аспектами труда» } \\
\hline 1.1 & $\begin{array}{l}\text { Уровень удовлетворенности заработной } \\
\text { платой }\end{array}$ & 0 & 1 & 2 & 3 & 4 \\
\hline 1.2 & $\begin{array}{l}\text { Уровень удовлетворенности системой соц. } \\
\text { защищенности }\end{array}$ & 0 & 1 & 2 & 3 & 4 \\
\hline 1.3 & $\begin{array}{l}\text { Уровень удовлетворенности санитарно- } \\
\text { гигиеническими условиями труда } \\
\end{array}$ & 0 & 1 & 2 & 3 & 4 \\
\hline 1.4 & $\begin{array}{l}\text { Уровень удовлетворенности организаци- } \\
\text { онно-трудовыми условиями труда }\end{array}$ & 0 & 1 & 2 & 3 & 4 \\
\hline 1.5 & $\begin{array}{l}\text { Степень удовлетворенности отношениями } \\
\text { в коллективе }\end{array}$ & 0 & 1 & 2 & 3 & 4 \\
\hline 1.6 & $\begin{array}{l}\text { Уровень удовлетворенности содержанием } \\
\text { и значимостью труда }\end{array}$ & 0 & 1 & 2 & 3 & 4 \\
\hline 1.7 & $\begin{array}{l}\text { Уровень удовлетворенности системой } \\
\text { вознаграждения и признания заслуг }\end{array}$ & 0 & 1 & 2 & 3 & 4 \\
\hline 1.8 & $\begin{array}{l}\text { Уровень удовлетворенности системой } \\
\text { карьерного развития }\end{array}$ & 0 & 1 & 2 & 3 & 4 \\
\hline 1.9 & $\begin{array}{l}\text { Уровень удовлетворенности системой } \\
\text { проф. развития } \\
\end{array}$ & 0 & 1 & 2 & 3 & 4 \\
\hline \multicolumn{2}{|r|}{ Итого по блоку } & \multicolumn{5}{|c|}{2,3} \\
\hline \multicolumn{7}{|c|}{2 блок: «Организационно-трудовые условия труда» } \\
\hline 2.1 & Уровень дисциплины труда & 0 & 1 & 2 & 3 & 4 \\
\hline 2.2 & Уровень исполнительской дисциплины & 0 & 1 & 2 & 3 & 4 \\
\hline 2.3 & Степень травматизма работников & 0 & 1 & 2 & 3 & 4 \\
\hline 2.4 & Степень оснащенности рабочих мест & 0 & 1 & 2 & 3 & 4 \\
\hline 2.5 & Степень механизации и автоматизации труда & 0 & 1 & 2 & 3 & 4 \\
\hline 2.6 & Степень творческих операций & 0 & 1 & 2 & 3 & 4 \\
\hline 2.7 & $\begin{array}{l}\text { Соотношение формальных и неформаль- } \\
\text { ных структур управления и т. д. }\end{array}$ & 0 & 1 & 2 & 3 & 4 \\
\hline
\end{tabular}


Окончание табл. 3.

\begin{tabular}{|c|c|c|c|c|c|c|}
\hline 2.8 & $\begin{array}{l}\text { Степень информированности работников } \\
\text { о мотивационных программах }\end{array}$ & 0 & 1 & 2 & 3 & 4 \\
\hline 2.9 & Система оценки мотивации персонала & 0 & 1 & 2 & 3 & 4 \\
\hline & Итого по блоку & \multicolumn{5}{|c|}{2,0} \\
\hline \multicolumn{7}{|c|}{3 блок: «Социально-психологические условия труда» } \\
\hline 3.1 & $\begin{array}{l}\text { Морально-психологический климат } \\
\text { в коллективе }\end{array}$ & 0 & 1 & 2 & 3 & 4 \\
\hline 3.2 & $\begin{array}{l}\text { Уровень конфликтности в отдельных } \\
\text { подразделениях и на предприятии в целом }\end{array}$ & 0 & 1 & 2 & 3 & 4 \\
\hline 3.3 & $\begin{array}{l}\text { Трудовая и общественная активность } \\
\text { работников }\end{array}$ & 0 & 1 & 2 & 3 & 4 \\
\hline 3.4 & $\begin{array}{l}\text { Уровень вовлеченности и лояльности } \\
\text { персонала и т. д. }\end{array}$ & 0 & 1 & 2 & 3 & 4 \\
\hline & Итого по блоку & \multicolumn{5}{|c|}{1,75} \\
\hline \multicolumn{7}{|c|}{4 блок: «Социальная защищенность персонала» } \\
\hline 4.1 & $\begin{array}{l}\text { Жилищные условия работников и членов } \\
\text { их семей }\end{array}$ & 0 & 1 & 2 & 3 & 4 \\
\hline 4.2 & $\begin{array}{l}\text { Степень обеспеченности детскими } \\
\text { дошкольными учреждениями }\end{array}$ & 0 & 1 & 2 & 3 & 4 \\
\hline 4.3 & $\begin{array}{l}\text { Степень обеспеченности медицинской } \\
\text { помощью }\end{array}$ & 0 & 1 & 2 & 3 & 4 \\
\hline 4.4 & $\begin{array}{l}\text { Степень обеспеченности путевками в са- } \\
\text { наторно-оздоровительные учреждения }\end{array}$ & 0 & 1 & 2 & 3 & 4 \\
\hline 4.5 & $\begin{array}{l}\text { Степень обеспеченности дополнительны- } \\
\text { ми пенсионными гарантиями и т. д. }\end{array}$ & 0 & 1 & 2 & 3 & 4 \\
\hline & Итого по блоку & \multicolumn{5}{|c|}{2,8} \\
\hline \multicolumn{7}{|c|}{5 блок: «Профессионально-квалификационная структура персонала» } \\
\hline 5.1 & Проф. уровень работников & 0 & 1 & 2 & 3 & 4 \\
\hline 5.2 & Уровень квалификации работников & 0 & 1 & 2 & 3 & 4 \\
\hline 5.3 & Степень общей культуры работников & 0 & 1 & 2 & 3 & 4 \\
\hline 5.4 & $\begin{array}{l}\text { Доля работников, которые прошли } \\
\text { повышение квалификации }\end{array}$ & 0 & 1 & 2 & 3 & 4 \\
\hline 5.5 & $\begin{array}{l}\text { Доля работников, имеющих с удовлетво- } \\
\text { рительные результаты аттестации }\end{array}$ & 0 & 1 & 2 & 3 & 4 \\
\hline & Итого по блоку & \multicolumn{5}{|c|}{2,8} \\
\hline & Сумма баллов & \multicolumn{5}{|c|}{78 из 136} \\
\hline & $\begin{array}{r}\text { Социальная эффективность системы } \\
\text { мотивации персонала депо }\end{array}$ & \multicolumn{5}{|c|}{$57 \%$} \\
\hline
\end{tabular}

В итоге выделены низкие показатели по таким блокам оценки, как:

- организационно-трудовые условия труда (2,0 балла);

- социально-психологические условия труда (1,75 балла). 
Таким образом, на основании полученных результатов оценки выделим основные проблемы в системе мотивации персонала, которые непосредственно влияют на уровень мотивации персонала в депо.

\section{Обсуждение результатов}

Выделены две проблемы, относящиеся к организационно-трудовым условиям труда: низкий уровень информированности персонала о мотивационных программах, а также отсутствие системы оценки мотивации персонала. Третья проблема, относящиеся к социально-психологическим условиям труда, заключается в низком уровне лояльности персонала и вовлеченности в трудовую и общественную активность. Между тем возрастание «роли человеческого фактора в современной компании предполагает, что компетентные и лояльные работники продолжают выполнять свои трудовые функции, несмотря на кризисные и другие отрицательные факторы» [9].

Таким образом, с целью повышения баллов исследуемых блоков оценки эффективности системы мотивации необходимо устранить выявленные проблемы, повлиявшие на низкие показатели рассматриваемой области.

Согласно проведенной оценке эффективности системы мотивации персонала Локомотивного эксплуатационного депо были предложены рекомендации и мероприятия по их устранению, приведенные в таблице 4.

Рассмотрим более подробно внедрение предложенных рекомендаций и мероприятий по устранению выявленных проблем в системе мотивации персонала. Первую и вторую проблему низкого уровня информированности персонала о мотивационных программах и низкого уровня лояльности персонала и вовлеченности в трудовую и общественную активность предлагается решить с помощью цифровой трансформации системы мотивации персонала на базе информационной платформы «Scored» для повышения вовлеченности сотрудников, уменьшения текучести и улучшения имиджа предприятия. 


\section{Таблицуа 4.}

\section{Рекомендации и мероприятия по решению проблем}

в системе мотивации персонала

\begin{tabular}{|c|c|c|c|}
\hline Проблемы & \begin{tabular}{|c|} 
Рекомендации \\
по решению про- \\
блемы \\
\end{tabular} & Мероприятия & $\begin{array}{c}\text { Результаты } \\
\text { после реализации } \\
\text { мероприятий }\end{array}$ \\
\hline $\begin{array}{l}\text { Низкий уровень } \\
\text { информирован- } \\
\text { ности персонала } \\
\text { о мотивацион- } \\
\text { ных программах }\end{array}$ & \multirow[t]{2}{*}{$\begin{array}{l}\text { Цифровая транс- } \\
\text { формация систе- } \\
\text { мы мотивации } \\
\text { персонала }\end{array}$} & \multirow{2}{*}{$\begin{array}{l}\text { Внедрение циф- } \\
\text { ровой платфор- } \\
\text { мы «Scored» } \\
\text { для повышения } \\
\text { вовлеченности } \\
\text { сотрудников, } \\
\text { уменьшения те- } \\
\text { кучести и улуч- } \\
\text { шения имиджа } \\
\text { предприятия }\end{array}$} & \multirow{3}{*}{$\begin{array}{l}\text { - повышение производитель- } \\
\text { ности труда за счет роста инте-- } \\
\text { реса у сотрудников к работе; } \\
\text { - рост трудовой активности } \\
\text { персонала; } \\
\text { - возникновение материаль- } \\
\text { ной заинтересованности в } \\
\text { развитии своих компетенций в } \\
\text { трудовой сфере; } \\
\text { - увеличение уровня мотива- } \\
\text { ции персонала; } \\
\text { - сохранение численного } \\
\text { и качественного состава } \\
\text { персонала; } \\
\text { - эффективная реализация } \\
\text { стратегии управления орга- } \\
\text { низации }\end{array}$} \\
\hline $\begin{array}{l}\text { Низкий уро- } \\
\text { вень лояльно- } \\
\text { сти персонала и } \\
\text { вовлеченности } \\
\text { в трудовую и } \\
\text { общественную } \\
\text { активность } \\
\end{array}$ & & & \\
\hline $\begin{array}{l}\text { Отсутствие си- } \\
\text { стемы оценки } \\
\text { мотивации пер- } \\
\text { сонала }\end{array}$ & $\begin{array}{l}\text { Внедрение эф- } \\
\text { фективной оцен- } \\
\text { ки системы моти- } \\
\text { вации персонала } \\
\text { в организации }\end{array}$ & $\begin{array}{l}\text { Внедрение сер- } \\
\text { виса НR Code } \\
\text { на основе ис- } \\
\text { кусственного } \\
\text { интеллекта }\end{array}$ & \\
\hline
\end{tabular}

Необходимость осуществления данного мероприятия обусловлена тем, что если «ранее предприятия выбирали кандидатов и люди расценивались как ресурсы, то сегодня персонал становится самым главным капиталом, и право выбора лучших условий труда перешло к сотрудникам и соискателям рабочих мест» $[15$, с. 9$]$. Платформы Scored гарантирует повышения внутренней лояльности персонала, учитывая следующие факторы:

- оптимизация производительности. Сервис позволяет устанавливать динамические цели по показателям эффективности персонала и вознаграждать любые действия сотрудников;

- уменышение текучести кадров. Платформа позволяет улучшить имидж компании, используя возможности персонализации и создавать долгосрочные сценарии развития персонала [10].

Также платформа Scored имеет гибкие процессы, а именно:

- интерактивный рабочий процесс. Прозрачный и актуальный портал мотивации для сотрудников, повышающий вовлеченность персонала; 
- возможность получить быстрые результаты. Сервис позволяет запустить программу мотивации без излишних затрат человеческих ресурсов на разработку и поддержку;

- Scored имеет доступный и гибкий интерфейс для управления программой, настройки механик и сбора аналитических данных. Платформа получает данные из внутренних систем учета и позволяет хранить данные о сотрудниках, их действиях и ключевых показателях [10].

Веб-интерфейс позволяет сотрудникам отслеживать свой прогресс, текущие вознаграждения, он может в любой момент получить актуальный статус и проще находить области для развития.

Особенности онлайн-платформы Scored:

- освобождение ресурсов HR - автоматическая обработка мотивационных механик позволяет освободить ресурс HR и направить его на оптимизацию программ мотивации;

- прозрачность и актуальность - портал сотрудника обеспечивает прозрачность и актуальность мотивационной программы, увеличивая заинтересованность и вовлеченность;

- аналитика - Scored агрегирует большой набор данных и позволяет формировать отчетность и аналитику с глубокими инсайтами в процессы мотивационных механик [10].

Таким образом, внедрение предлагаемого цифрового сервиса позволит в эксплуатационном депо повысить уровень информированности персонала о мотивационных программах, а также непосредственно увеличить степень лояльности персонала и вовлеченности в трудовую и общественную активность, что, в свою очередь, окажет влияние на качество работы персонала.

Третью проблему в исследуемой области - отсутствия оценки системы мотивации предлагается решить с помощью внедрения сервиса HR Code, работающего на основе искусственного интеллекта, позволяющего провести тестирование уровня мотивации персонала.

HR Code - система, которая позволяет определить, что мотивирует людей хорошо работать, как справляться с ошибками сотрудников и как их эффективно поощрять. На основании результа- 
тов тестов сервис выдает мотивационные потребности работника, которые показывают, нужны ли ему деньги, уважение, карьерный рост или что-то еще. Система предлагает награду за хорошую работу - повышение зарплаты, бесплатное обучение, место на доске почета и так далее. Также она выбирает и возможное наказание например, лишение премии или рутинные задачи [4].

Преимуществами данного сервиса являются:

- снижение расходов на заработную плату;

- снижение текучести кадров;

- индивидуальный подход к каждому сотруднику;

- минимизация конфликтов в коллективе;

- выполнение плана сотрудниками;

- уменьшение количества больничных;

- повышение производительности труда и качества работы персонала.

Тестирование с помощью HR Code проходит в три этапа:

- рассылка приглашений на тесты по е-mail (имеется специальная форма для заполнения е-таil адресов);

- прохождение сотрудниками тестирования (а также заполнение анкеты с личными данными: ФИО, отдел, должность в компании);

- получение результатов в таблице (мотивация работников, виды поощрений и другая информация) [4].

Разработчики HR Code утверждают следующее: эффективно выстроив систему мотивации, руководители увеличат производительность труда на 25\%, что подтверждено исследованиями В. И. Герчикова российских компаний [3].

\section{Выводы}

Предлагаемые корректирующие мероприятия позволят не только повысить общую социальную эффективность системы мотивации персонала, но и обеспечить рост уровня информированности персонала о мотивационных программах, а также непосредственно увеличить степень лояльности персонала и вовлеченности в 
трудовую и общественную активность, что, в свою очередь, окажет значительное влияние на качество работы персонала.

Опыт проведения оценки системы мотивации персонала может быть полезен в других региональных структурных подразделениях локомотивного хозяйства ОАО «РЖД».

\section{Список литературы}

1. Обучение персонала как инструмент развития человеческого потенциала в условиях цифровой трансформации / Вашко Т.А., Максименко И.А., Шендель Т.В., Якимова Л.Д., Яркова С.А. Красноярск, 2021. 204 с.

2. Воротникова Т.С. Исследование системы мотивации труда филиала ОАО «Российские Железные Дороги» // Экономика и управление в XXI веке : тенденции развития. Сборник материалов XXXVII Международной научно-практической конференции. 2017. С. 68-74.

3. Гайфуллина М.М., Муртазина Д.Д. Методический подход к оценке эффективности системы мотивации и стимулирования персонала // Международный журнал гуманитарных и естественных наук. 2018. №4. С. 192-194.

4. Клочков А.П. КРІ и мотивация персонала : полный сборник практических инструментов. М., 2018. 109 с.

5. Когдин А.А. Мотивация и стимулирование трудовой деятельности в управлении персоналом // Основы экономики, управления и права. 2018. № 4. С. 80-83.

6. Кузнецова А.Ю. Методология оценки эффективности системы мотивации персонала // Научный аспект : Институт экономики и управления Белгородского государственного национального исследовательского университета. 2018. № 4 (4). С. 486-490.

7. Инновационный менеджмент: к вопросу о повышении инновационной восприимчивости персонала / Кутузова А.В., Яркова С.А., Якимова Л.Д., Мельникова Е.В. // Наука Красноярья. 2020. Т. 9. № 1. С. 125-145.

8. Макарова Е.А., Голубева М.М. Исследование мотивации персонала: отечественный и зарубежный опыт // Вестник ТИУиЭ. 2017. №2 (26). C.14-18. 
9. Медведев М.О., Серикова О.Ю. Имидж организации как инструмент формирования лояльности персонала // Менеджмент и маркетинг: теория и практика. Сборник научных статей. Чебоксары. 2018. C. 513-517.

10. Мотивация персонала как инструмент управления качеством труда // Агро Кебеты. 2020. https://blog.agrokebety.com/motivatsiyapersonala-kak-instrument-upravleniya-kachestvom-truda (дата обращения: 27.02.2021).

11. Розманов А.В., Малахова А.А., Серикова О.Ю. Отечественный и зарубежный опыт мотивации персонала // Образование - наука производство. Материалы Всероссийской научно-практической конференции. 2018. С. 70-75.

12.Серикова О.Ю., Малахова А.А., Цоменко Д.Б. Исследование мотивации персонала в кадровом менеджменте // Инновационные технологии на железнодорожном транспорте. Труды XXII Межвузовской научно-практической конференции КрИЖТ ИрГУПС. 2018. C. 173-178.

13.Тарасова К.И., Асатурова Ю.М. Мотивация и стимулирование трудовой деятельности в управлении персоналом // Санкт-Петербургский политехнический университет Петра Великого. 2017. C. $167-170$.

14.Разработка инструментов оценки персонала по уровню клиентоориентированности / Яркова С.А., Данилова А.С., Анисимова Н.А., Якимова Л.Д. // Экономика труда. 2018. Т. 5. № 3. C. 911-924.

15. Анализ формирования имиджа организации-работодателя на рынке труда как фактора привлечения потенциальных работников / Яркова С.А., Романцова Ю.Д., Якимова Л.Д., Малахова А.А. // Наука Красноярья. 2018. Т. 7. № 2. С. 7-25.

16. Competency-based approach to internal corporate social responsibility implementation in Russian railways /Yakimova L.D., Yarkova S.A., Melnikova E.V., Malakhova A.A. // European Proceedings of Social and Behavioural Sciences EpSBS. Krasnoyarsk Science and Technology City Hall. Krasnoyarsk, 2020. P. 612-618. 


\section{References}

1. Vashko T.A., Maksimenko I.A., SHendel' T.V., YAkimova L.D., YArkova S.A. Obuchenie personala kak instrument razvitiya chelovecheskogo potenciala $v$ usloviyah cifrovoj transformacii [Personnel training as a tool for human development in the context of digital transformation]. Krasnoyarsk, 2021, 204 p.

2. Vorotnikova T.S. Issledovanie sistemy motivacii truda filiala «Rossijskie ZHeleznye Dorogi» [Study of the labor motivation system of the branch of JSC Russian Railways]. Ekonomika i upravlenie $v$ XXI veke : tendencii razvitiya. Sbornik materialov XXXVII Mezhdunarodnoj nauchno-prakticheskoj konferencii [Economics and Management in the XXI Century: Development Trends. Collection of materials of the XXXVII International Scientific and Practical Conference], 2017, pp. 68-74.

3. Gajfullina M.M., Murtazina D.D. Metodicheskij podhod k ocenke effektivnosti sistemy motivacii i stimulirovaniya personala [Methodological approach to assessing the effectiveness of the system of motivation and incentives for personnel]. Mezhdunarodnyj zhurnal gumanitarnyh $i$ estestvennyh nauk [International Journal of Humanities and Natural Sciences], 2018, no. 4, pp. 192-194.

4. Klochkov A.P. KPI i motivaciya personala : polnyj sbornik prakticheskih instrumentov [Key performance indicators and employee motivation: a complete compendium of practical tools]. Moscow, 2018, 109 p.

5. Kogdin A.A. Motivaciya i stimulirovanie trudovoj deyatel'nosti v upravlenii personalom [Motivation and stimulation of labor activity in personnel management]. Osnovy ekonomiki, upravleniya i prava [Fundamentals of Economics, Management and Law]. 2018, no. 4, pp. 80-83.

6. Kuznetsova A.Yu. Metodologiya ocenki effektivnosti sistemy motivacii personala [Methodology for assessing the effectiveness of the personnel motivation system]. Nauchnyj aspekt : Institut ekonomiki $i$ upravleniya Belgorodskogo gosudarstvennogo nacional'nogo issledovatel'skogo universiteta [Scientific aspect: Institute of Economics and Management, Belgorod State National Research University], 2018, no. 4 (4), pp. 486-490. 
7. Kutuzova A.V., Yarkova S.A., Yakimova L.D., Melnikova E.V. Innovacionnyj menedzhment: $\mathrm{k}$ voprosu o povyshenii innovacionnoj vospriimchivosti personala [Innovation management: on the issue of increasing the innovative susceptibility of personnel]. Nauka Krasnoyar'ya [Science of Krasnoyarsk], 2020, vol. 9, no. 1, pp. 125-145.

8. Makarova E.A., Golubeva M.M. Issledovanie motivacii personala: otechestvennyj i zarubezhnyj opyt [Research of personnel motivation: domestic and foreign experience]. Vestnik TIUiE. [Bulletin of TIUiE], 2017, no. 2 (26), pp. 14-18.

9. Medvedev M.O., Serikova O.Yu. Imidzh organizacii kak instrument formirovaniya loyal'nosti personala [The image of the organization as a tool for the formation of personnel loyalty]. Menedzhment i marketing: teoriya i praktika. Sbornik nauchnyh statej [Management and marketing: theory and practice. Collection of scientific articles]. Cheboksary, 2018, pp. 513-517.

10. Motivaciya personala kak instrument upravleniya kachestvom truda [Personnel motivation as a tool for labor quality management]. Agro Kebeta. 2020. https://blog.agrokebety.com/motivatsiya-personala-kak-instrument-upravleniya-kachestvom-truda (accessed 27.02.2021).

11. Rozmanov A.V., Malakhova A.A., Serikova O.Yu. Otechestvennyj i zarubezhnyj opyt motivacii personala [Domestic and foreign experience of personnel motivation]. Obrazovanie - nauka - proizvodstvo. Materialy Vserossijskoj nauchno-prakticheskoj konferencii [Education - science - production. Materials of the All-Russian Scientific and Practical Conference], 2018, pp. 70-75.

12. Serikova O.Yu., Malakhova A.A., Tsomenko D.B. Issledovanie motivacii personala $\mathrm{v}$ kadrovom menedzhmente [Research of personnel motivation in personnel management]. Innovacionnye tekhnologii na zhe-leznodorozhnom transporte. Trudy XXII Mezhvuzovskoj nauchno-prakticheskoj konferencii KrIZHT IrGUPS [Innovative technologies in railway transport. Proceedings of the XXII Interuniversity Scientific and Practical Conference KRIZhT IrGUPS], 2018, pp. 173-178.

13. Tarasova K.I., Asaturova Yu.M. Motivaciya i stimulirovanie trudovoj deyatel'nosti $\mathrm{v}$ upravlenii personalom [Motivation and stimulation of 
labor activity in personnel management]. Sankt-Peterburgskij politekhnicheskij universitet Petra Velikogo [Peter the Great St. Petersburg Polytechnic University], 2017, pp.167-170.

14. Yarkova S.A., Danilova A.S., Anisimova N.A., Yakimova L.D. Razrabotka instrumentov ocenki personala po urovnyu klientoorientirovannosti [Development of tools for assessing personnel by the level of customer focus]. Ekonomika truda [Labor Economics], 2018, vol. 5, no. 3, pp. 911-924.

15. Yarkova S.A., Romantsova Yu.D., Yakimova L.D., Malakhova A.A. Analiz formirovaniya imidzha organizacii-rabotodatelya na rynke truda kak faktora privlecheniya potencial'nyh rabotnikov [Analysis of the formation of the image of an employer organization in the labor market as a factor in attracting potential employees]. Nauka Krasnoyar 'ya [Science of Krasnoyarsk], 2018, vol. 7, no. 2. pp. 7-25.

16. Yakimova L.D., Yarkova S.A., Melnikova E.V., Malakhova A.A. Competency-based approach to internal corporate social responsibility implementation in Russian railways. European Proceedings of Social and Behavioural Sciences EpSBS. Krasnoyarsk Science and Technology City Hall. Krasnoyarsk, 2020, pp. 612-618.

\section{ДАННЫЕ ОБ АВТОРАХ}

Серикова Олеся Юрьевна, старший преподаватель

Красноярский институт железнодорожного транспорта филиал Иркутского государственного университета путей сообщения

ул. Новая Заря, 2u, г. Красноярск, 660028, Российская Федерация

\section{Мартышев Артём Викторович, бакалавр}

Красноярский институт железнодорожного транспорта филиал Иркутского государственного университета путей сообщения

ул. Новая Заря, 2u, г. Красноярск, 660028, Российская Федерачия 
Якимова Любовь Дмитриевна, канд. техн. наук, доцент

Красноярский институт железнодорожного транспортафилиал Иркутского государственного университета путей сообщения

ул. Новая Заря, 2u, г. Красноярск, 660028, Российская Федерация

lyubov-yakimova@yandex.ru

\section{DATA ABOUT THE AUTHORS}

\section{Olesya Yu. Serikova, Senior Lecturer}

Krasnoyarsk Institute of Railway Transport - branch of the Irkutsk State University of Railways

2i, Novaya Zarya Str., Krasnoyarsk, 660028, Russian Federation SPIN-code: 2264-0689

ORCID: 0000-0001-6820-2053

\section{Artyom V. Martyshev, Bachelor}

Krasnoyarsk Institute of Railway Transport - branch of the Irkutsk State University of Railways

2i, Novaya Zarya Str., Krasnoyarsk, 660028, Russian Federation

Lyubov D. Yakimova, Candidate of Engineering Sciences, Associate Professor;

Krasnoyarsk Institute of Railway Transport - branch of the Irkutsk State University of Railways

2i, Novaya Zarya Str., Krasnoyarsk, 660028, Russian Federation lyubov-yakimova@yandex.ru

SPIN-code: 4077-0410

ORCID: 0000-0002-0778-3955 